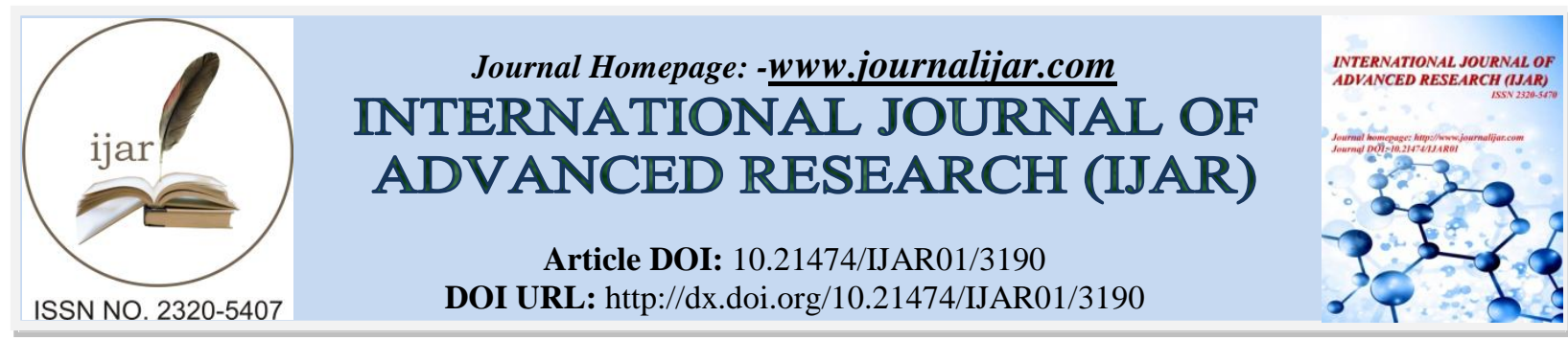

RESEARCH ARTICLE

\title{
COMPARISON OF SEMG SIGNAL OF CTS SUFFERERS AND NON CTS SUFFERERS
}

\author{
Md. Sarfaraz Alam ${ }^{1}$, Dr. Urmi Ravindra Salve ${ }^{1}$, Naresh Kumar ${ }^{2}$, Dr.Zulquernain Mallick ${ }^{3}$ and Dr. Manoj \\ Kumar'. \\ 1. Department of Design, Indian Institute of Technology Guwahati,Guwahati, India. \\ 2. Department of ME, Sant Longowal Institute of Engineering \& Technology, Sangrur, Punjab, India. \\ 3. Department of ME, Faculty of Engineering \& Technology Jamia Millia Islamia, New Delhi, India.
}

\section{Manuscript Info}

Manuscript History

Received: 07 December 2016

Final Accepted: 12 January 2017

Published: February 2017

Key words:-

Repetitive strain injury, CTS, surfaceelectromyography Signal, APB muscle

\begin{abstract}
Repetitive strain injuries (RSI) are the nation's most common and costly occupational health problem, affecting hundreds of thousands of American workers, and costing more than $\$ 20$ billion a year in workers compensation. The common musculoskeletal disorders are associated with Abductor Pollicis Brevis (APB), often included in the list of the Repetitive Strain Injury (RSI), affecting as much as 5\% of adult population. But in the majority of cases, the condition is idiopathic. In this paper, the health surveillance has been conducted on 66 Non-CTS Sufferers and 37 CTS Sufferers connecting rod manufacturing works. A study of the signals of the Abductor Pollicis Brevis (APB), muscle with different conditions such as rest position and different movements of hand has been carried out using surface-electromyography (sEMG).Experiments were performed on BIOPAC MP-45 instrument and independent two samplet-test outputs from SPSS analysis using sEMG signals obtained were analyzed for severity of the problem. So, Results reveal that non-CTS sufferers worker have better sEMG signal than CTS sufferers worker and are less prone to carpal tunnel syndrome.
\end{abstract}

Copy Right, IJAR, 2017,. All rights reserved.

\section{Introduction:-}

Repetitive Strain Injury (RSI) is a generic term and often used to describe work-related musculoskeletal disorders (Kemp et al., 2002). RSI is an umbrella term used to describe a number of specific musculoskeletal conditions, i.e. Carpal Tunnel syndrome (CTS), as well as 'diffuse RSI', which is more difficult to define. These conditions are often occupational in origin. Lack of adequate diagnosis or access to appropriate treatment can bring the conditions and sometimes leads to job loss and economic hardship (Gagne et al., 2010). RSI is the more commonly known term for a set of disorders called Work Related Upper Limb Disorders (WRULD'S). RSI covers a wide range of injuries to muscles, tendons and nerves. Usually hands, wrists, elbows or shoulders are affected but knees and feet may also suffers especially if a job involves a lot of kneeling or operating foot pedals on equipment.

The highest percentage of work injuries resulting from repetitive motion occurs in the manufacturing sector, where assembly-line works are common (Keller et al., 1998) RSI's must be treated at an early stage or a permanent disability could be caused which can cause a loss in term of compensation, productivity and number of working hours/days. Signs and symptoms vary, depending on type of jobs and which part of the body is affected. Initially,

Corresponding Author:- Md. Sarfaraz Alam. 
symptoms may only occur when the individual is doing the repetitive task - they will slowly go away when the person rests. Eventually, though, symptoms may be present all the time, if left untreated. The most common RSI signs and symptoms include: Tenderness in the affectedmuscle or joint, Pain in the affected muscleor joint, A throbbing (pulsating) sensationin the affected area, Pins and needles (tingling)in the affected area, especiallythe hand or arm, Loss of sensation in thehand, Loss of strength in the hand, Weakness, lack of endurance (Gagne et al., 2010).RSI is caused, by continuous repetitive and forceful work, hand or arm movements, i.e. hammering pushing, pulling, lifting or reaching movements, too fast or extreme workloads, long hours, lack of variety or breaks, awkward grips or positions, imperfectly designed equipment and/or poor working environments. Other synonyms for RSI include: Cumulative Trauma Disorder (CTD), Occupational Overuse Syndrome (OOS) and Repetitive Motion Syndrome (RMS).The more specific disorders are CTS, Tendonitis, and Tenosynovitis,Dupuytren's contracture,Epicondylitisor 'tennis elbow',Bursitis and a host of others. Of course, CTS is the most common problem brought on by repetitive hand motion.

\section{Experimentation:-}

The study subjects were recruited from connecting rod manufacturing unit of a manufacturing industry. The population included all the unit workers irrespective of age, gender or ethnic group. All full-time workers with at least 6 months on the job were invited to participate in the study. Of the 113 eligible workers, 103 agreed to participate $(91 \%)$ in the study. So a sample size of 103 workers was used $(\mathrm{N}=103)$.

\section{Surface electromyography:-}

The terms carpal tunnel syndrome, cumulative trauma disorders, ergonomic disorders, repetitive strain injuries and repetitive motion injuries all refer to the same disorder of the wrist and hand (Kumar et al., 2010). CTS is brought on by over-worked, over-strained muscles of arms and hands, resulting in a loss of nerve conductivity and possibly leading to muscle strength problems (Montgomery, 1995). Human skeletal muscle consists of hundreds of individual cylindrically shaped cells (called fibers) bounded together by connective tissue. In the body, skeletal muscles are stimulated to approach motor nerves that carry signals in the form of nerve impulses from the brain. The combination of a single motor neuron and all of the muscle fibers it controls is called a motor unit. When an increase in the strength of a muscle's contraction is necessary to perform a task, the brain increases the number of active motor units within the muscle (Okada et al., 2000).

Although the electrical impulse generated and conducted by each fiber is very weak (less than 100 micro volts), many fibers conducting simultaneously induce voltage differences in the overlying skin that are large enough to be detected by surface electrodes. The detection, amplification and recording of changes in skin voltage produced by underlying skeletal muscle contraction are called electromyography. The recording thus obtained is called Electromyogram. The APB (Abductor PollicisBrevis) is a member of the thenar muscles and is often affected by muscle antropy associated with CTS (Wunderlich, 1993). EMG signal means a collective electrical signal from musculoskeletal system, skeletal muscles which represent the electrical activity of muscles during contraction. In recent years, there has been a tremendous interest in introducing intuitive interfaces that can recognize the user's body movements and translate them in to machine commands. The EMG signal is stochastic in nature and it becomes difficult to quantify and interpret the processed signal. Nerves and muscles create electrical signals that deliver messages to and from the brain. Injuries and diseases can affect nerves and muscles, which can slow down the movements of these electrical signals. The two tests that are done more often to measure the speed and degree of electrical activity in muscles and nerves are EMG and Nerve Conduction Study (NCS). NCS is often done along with EMG. In NCS electrodes are taped to the skin along the nerve pathway. Then the nerve is stimulated with electric current. The electrodes will record how fast the signal is travelling. This test helps to determine the specific site of the injury to the nerves.

\section{Analysis based on EMG signal:-}

Myoelectric signal represents the electrical activity of muscles and signal value is represented in micro volts obtained by surface electromyography (sEMG) technique. sEMG signals have been taken by BIOPAC MP-45 data acquisition unit. The MP unit is an electrically isolated data acquisition unit, designed for biophysical measurements. The MP45 receives power from the computer (USB port).The MP Unit has an internal microprocessor to control data acquisition and communication with the computer. The MP Unit takes incoming signals and converts them into digital signals that can be processed with the computer. There are analog input channels (two on MP45), one of which can be used as a trigger input. 
In the present study, workers have been examined by the BIOPAC MP45 instrument. To take readings from the muscles of a subject three electrodes are used. Positions of three electrodes during sEMG data collection are shown in the Figure 1 and Figure 2.

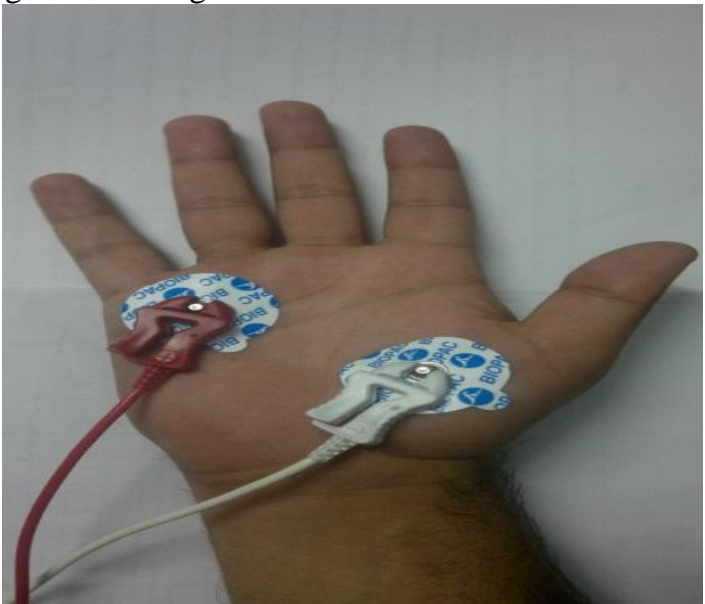

Fig. 1:- Position of negative (white)

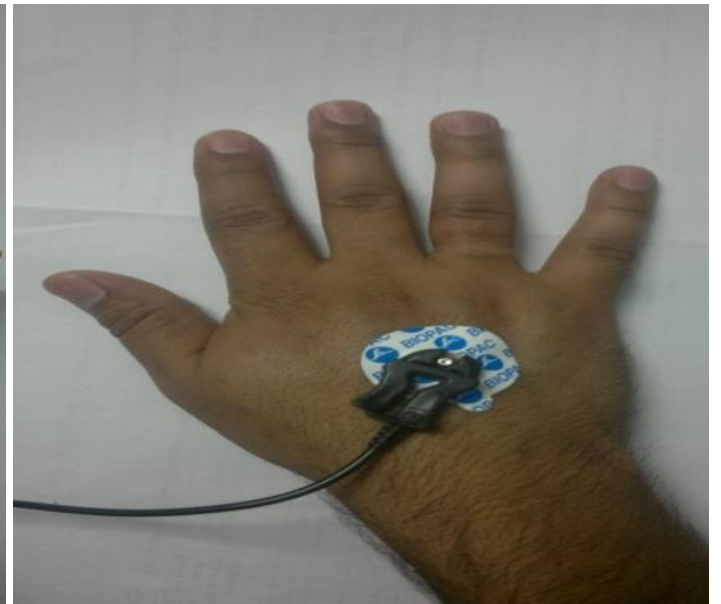

Fig. 2:- Position of ground electrode and positive (red) electrode

The negative electrode (white) is placed on APB muscle and positive electrode (red) is placed 6 to $10 \mathrm{~cm}$ away from negative electrode. The third electrode (black) is grounded. An EMG reading of APB muscle of dominant hand is recorded for 3 minutes $(180 \mathrm{sec}$.) for a series of clenching first as hard as possible, and then followed by release. For analysis, the sEMG signals readings are taken from 140 seconds to 160 seconds from each worker.From the EMG data the values of Raw-EMG, Integrated-EMG and Root-mean square EMG are obtained. Raw-EMG i.e. the unprocessed signal of amplitude between $0-6 \mathrm{mV}$ is measured from peak to peak and represents the amount of muscle energy measured. Raw-EMG signal i.e. the signals which is unprocessed form of the sEMG signals helps mostly in qualitative analysis.Integrated-EMG is calculation of area under the rectified signal. Values are summed over the specified time then divided by the total number of values. Values will increase continuously over time. It quantifies the muscle activity means it tells about the movement of hand through the electrical signal by which one can identify how well the APB muscle is working. Root-mean square EMG (EMG-RMS) values are calculated by squaring each data point, summing the squares, dividing the sum of squares by number of observations, and taking the square root and it represent the quantification of muscle activity.

The abductorpollicisbrevis (APB) is a member of the thenar muscles and is often affected by muscle atrophy associated with carpal tunnel syndrome (CTS). The electrophysiological properties of the APB muscle are still not well understood. Reliable information about the physiological fatigue behavior of the APB muscle could be valuable to recognize changes in a pathologically altered muscle, as for instance in the case of CTS. However, to apply this information in a clinical setting it is essential to work with non-invasive diagnostic techniques whenever possible. Fortunately, considerable progress has been made in the past decades to develop non-invasive techniques to evaluate the performance of a muscle by recording and processing surface electromyograms (sEMG).

Based on literature it is clear that sEMG is a technique, which is used to check the performance of the APB muscle with the help of electrical signals. In this study, a comparison was done with the help of mean of sEMG signals between the CTS sufferers and non CTS sufferer workers in the manufacturing industry. The average root mean square values of the electromyogram signals were taken (Appendix 1).

The independent two samplet-test is used is used to check the statistical significance. The independent sample t-test is used because there are two separate samples of people which are to be compared. First sample is people who don't have CTS and second is who have CTS. There is no overlapping between the two samples.

The total number of workers is divided into two groups depending on the presence of CTS. Those who don't have CTS symptoms are assigned label ' 0 ' and those who have CTS symptoms are assigned label ' 1 '.

Group 1 (' 0 ' in the datasheet) has NO CTS.

Group 2 (' 1 ' in the datasheet) has CTS. 
The hypothesis assumed in the analysis is as follows:

- $\quad$ Null Hypothesis $\mathrm{H}_{0}$ : Mean RMS sEMG value for Group1 = Mean RMS sEMG value for Group 2.

- $\quad$ Alternative Hypothesis $\mathrm{H}_{\mathrm{A}}$ : Mean RMS sEMG value for Group1 $\neq$ Mean RMS sEMG value for Group 2.

In the analysis, CTS is grouping variable and sEMG value is test variable. The group statistics for CTS sufferers and non CTS sufferers is shown in the Table 1.

Table 1:- Group statistics from SPSS

\begin{tabular}{|c|c|c|c|c|c|}
\hline \multicolumn{7}{|c|}{ Group Statistics } \\
\hline \multirow{2}{*}{ sEMG } & CTS & $\mathrm{N}$ & Mean & Std. Deviation & Std. Error Mean \\
\cline { 2 - 7 } & Non CTS Sufferers & 66 & .07005718 & .151573803 & .018657445 \\
\hline
\end{tabular}

It can be concluded from Table 1 that mean RMS sEMG value for non CTS sufferers is more than mean RMS sEMG value for CTS sufferers. Now, it has to be checked whether there is any significant difference between the two values. Final results for independent sample test are shown in the Table 2.

Table 2:- Independent two samples t-test output from SPSS

\begin{tabular}{|c|c|c|c|c|c|c|c|c|c|c|}
\hline \multicolumn{11}{|c|}{ Independent Samples Test } \\
\hline & & \multicolumn{2}{|c|}{$\begin{array}{l}\text { Levene's Test } \\
\text { for } \\
\text { Equality of } \\
\text { Variances }\end{array}$} & \multicolumn{7}{|c|}{ t-test for Equality of Means } \\
\hline & & \multirow[t]{2}{*}{$\mathrm{F}$} & \multirow[t]{2}{*}{ Sig. } & \multirow[t]{2}{*}{$\mathrm{T}$} & \multirow[t]{2}{*}{ Df } & \multirow[t]{2}{*}{$\begin{array}{l}\text { Sig. } \\
(2- \\
\text { tailed })\end{array}$} & \multirow[t]{2}{*}{$\begin{array}{l}\text { Mean } \\
\text { Difference }\end{array}$} & \multirow[t]{2}{*}{$\begin{array}{l}\text { Std. Error } \\
\text { Difference }\end{array}$} & \multicolumn{2}{|c|}{$\begin{array}{l}\text { 95\% Confidence } \\
\text { Interval of the } \\
\text { Difference }\end{array}$} \\
\hline & & & & & & & & & Lower & Upper \\
\hline \multirow[t]{2}{*}{ sEMG } & $\begin{array}{l}\text { Equal } \\
\text { variances } \\
\text { assumed }\end{array}$ & 7.284 & .008 & 1.572 & 101 & .119 & .0399 & .0254 & -.0104 & .0903 \\
\hline & $\begin{array}{l}\text { Equal } \\
\text { variances } \\
\text { not } \\
\text { assumed }\end{array}$ & & & 2.029 & 78.638 & .046 & .0399 & .0196 & .0007 & .0790 \\
\hline
\end{tabular}

\section{Result:-}

From the result of F-test, it is clear that sig. (p-value) is found to be 0.08 which is less than 0.05 . So the variances are not assumed to be equal and bottom row of the t-test will be used for analysis. As p-value (0.46) is less than 0.05 , null hypothesis can be rejected and alternative hypothesis can be accepted.

Therefore it can be concluded that there is significant difference between the sEMG values of two groups of workers. Accepting alternative hypothesis means having CTS does affect the sEMG value of the workers. So Healthy workers have better sEMG signal and are less prone to carpal tunnel syndrome.

\section{Conclusion:-}

In the present analysis it has been demonstrated that the people with a particular occupations, can identify their problem of CTS, deciphered by sEMG signals analysis. Comparison of sEMGsignals (during expansion and contraction of APB muscle of different subjects) give indication of changes, not well understood so far. sEMG signals seem to have good repeatability but average validity in the analysis of some concrete relationships, due to lack of availability of standard data. So, this analysis it has been found thatindependent two sample t-test was used to analyze the sEMG signals of APB muscle which shows that non CTS sufferers have better sEMG signal than that of CTS sufferers and are more prone to potential CTS symptoms. Further there is scope of extending the work in different occupation, age groups, environmental conditions, and postures to analyze muscles conditions and identify the problems related to that. 


\section{Acknowledgment:-}

Authors are thankful to the EMSON Tools Manufacturing Corp. Ltd. for conduct this study.

\section{References:-}

1. A. Rainoldi, M. Gazzoni, R. Casale (2008): Surface EMG signal alterations in Carpal Tunnel syndrome: a pilot study. Eur J ApplPhysiol, 10:233-242

2. Gagne R. (2010): Repetitive Strain Injury (RSI) Review of proactive measures to reduce costs and future injury rates. Fit2WRK Clinical Educational Series Vol., 1-11

3. Kumar M., Kumar M., Kumar S., Jindal O., AroraShatru A. and Kumar R., (2010):Analysis of APB Muscle by Surface Electromyography. International Journal of Engineering Studies. 2:305-312

4. Montgomery, K., (1995) A non-surgical approach to carpal tunnel syndrome. International forum of new science, 13-17

5. Okada, M., Tsubata, O., Yasumato, S., Toda, N., and Matsumoto, T. (2000): Clinical study of surgical treatment of carpal tunnel syndrome: Open versus endoscopic technique. Journal of orthopaedic surgery, 8:19-25

6. Ron G Gorsche, J Preston Wiley, Ralph F Renger, Rollin F Brant, Tara Y Gemer, Treny M Sasyniuk (1999): Prevalence and incidence of carpal tunnel syndrome in a meat packing plant.Occup Environ Med.,56:417- 422

7. Scott Day "Important Factors in Surface EMG Measurement" Bortec Biomedical Ltd.

8. ShyamalKoley, NavdeepKaur and J.S. Sandhu (2009): A Study on Hand Grip Strength in Female Labourers of Jalandhar, Punjab, India. J Life Sci., 1(1):57-62

9. T.P. Green, E.U. Tolonen, M.R.A. Clarke, P. Pathak, M.L. Newey, and C.J. Kershaw, M.A. Kallio (2012): The relationship of pre- and postoperative median and ulnar nerve conduction measures to a self-administered questionnaire in carpal tunnel syndrome. Neurophysiologie Clinique/Clinical Neurophysiology, 20:1-9

10. Taha, Z., Nazaruddin. (2005): Grip strength prediction for Malaysian industrial workers using artificial neural networks. International journal of industrial ergonomics, 35-807-816

11. Vessey MP, Villard-Mackintosh L, Yeates D. (1990): Epidemiology of carpal tunnel syndrome in women of childbearing age: findings in a large cohort study. Int J. ggg Epidemiol, 19:655-659

12. Van Rijn R, Huisstede B, Koes B, Burdorf A. (2009): Associations between work-related factors and the carpal tunnel syndrome - a systematic review. Scandinavian Journal of Work, Environment and Health, 35: 19-36

13. Wunderlich R. C. (1993): The natural treatment of carpal tunnel syndrome. Keats publishing Inc.

14. Wenzhou Yu, Ignatius T.S. Yu, Zhimin Li , Xiaorong Wang, Trevor Sun, Hui Lin, Sabrina Wan, Hong Qiu, ShaohuaXie (2012): Workrelated injuries and musculoskeletal disorders among factory workers in a major city of China. Accident Analysis and Prevention, 48:457-463

15. Werner RA, Albers JW, Franzblau A, Armstrong TJ. (1994): The relationship between body mass index and the diagnosis of carpal tunnel syndrome. Muscle Nerve, 17:632636

16. Yves R., Jean M., Corinne D., Serge F. and Dominique P. (2001): Prevalence incidence and risk factors of carpal tunnel syndrome in a large footwear factory. International Journal of Occupational Medicine and Environmental Health, Vol. 14, 4:357-367

17. Zetterberrg C., Torsten O., (1999): Carpal tunnel syndrome and other wrist hand symptoms and sign in male and female car assembly worker. International Journal of Ergonomics, 23 (2):193-204 


\begin{tabular}{|c|c|c|c|c|c|}
\hline (APPENDIX 1) & NDIX 1) & & & & \\
\hline & \multicolumn{4}{|c|}{ RMS-MEAN sEMG data of healthy and non- healthy workers } & \\
\hline \multicolumn{2}{|c|}{ Non healthy workers } & & \multicolumn{2}{|c|}{ Healthy workers } & \\
\hline \multirow[t]{2}{*}{ S. NO. } & RMS MEAN sEMG & \multirow[t]{2}{*}{ S.NO } & RMS MEAN sEMG value & \multirow[t]{2}{*}{ S.NO. } & RMS MEAN sEMG \\
\hline & value & & & & value \\
\hline 1 & 0.003561 & 1 & 0.229242 & 38 & 0.047049 \\
\hline 2 & 0.011972 & 2 & 0.035071 & 39 & 0.416252 \\
\hline 3 & 0.002914 & 3 & 0.008166 & 40 & 0.002916 \\
\hline 4 & 0.021027 & 4 & 0.026601 & 41 & 0.014034 \\
\hline 5 & 0.066239 & 5 & 0.006011 & 42 & 0.006975 \\
\hline 6 & 0.023969 & 6 & 0.023985 & 43 & 0.022483 \\
\hline 7 & 0.045408 & 7 & 0.00624 & 44 & 0.021614 \\
\hline 8 & 0.053379 & 8 & 0.031775 & 45 & 0.033068 \\
\hline 9 & 0.0117973 & 9 & 0.009782 & 46 & 0.014407 \\
\hline 10 & 0.02293 & 10 & 0.056974 & 47 & 0.035906 \\
\hline 11 & 0.23347 & 11 & 0.036557 & 48 & 0.035078 \\
\hline 12 & 0.036593 & 12 & 0.035497 & 49 & 0.036234 \\
\hline 13 & 0.015189 & 13 & 0.001964 & 50 & 0.0266 \\
\hline 14 & 0.019167 & 14 & 0.003561 & 51 & 0.035062 \\
\hline 15 & 0.044312 & 15 & 0.022034 & 52 & 0.036339 \\
\hline 16 & 0.015734 & 16 & 0.014067 & 53 & 0.022962 \\
\hline 17 & 0.001964 & 17 & 0.025286 & 54 & 0.051191 \\
\hline 18 & 0.0185 & 18 & 0.281626 & 55 & 0.066274 \\
\hline 19 & 0.00978 & 19 & 0.04429 & 56 & 0.00951 \\
\hline 20 & 0.036601 & 20 & 0.044323 & 57 & 0.021052 \\
\hline 21 & 0.020038 & 21 & 0.004225 & 58 & 0.010771 \\
\hline 22 & 0.019175 & 22 & 0.007265 & 59 & 0.009762 \\
\hline 23 & 0.009786 & 23 & 0.022483 & 60 & 0.181913 \\
\hline 24 & 0.066042 & 24 & 0.025662 & 61 & 0.181948 \\
\hline 25 & 0.001964 & 25 & 0.033041 & 62 & 0.036315 \\
\hline 26 & 0.026136 & 26 & 0.03267 & 63 & 0.006207 \\
\hline 27 & 0.036595 & 27 & 0.75911 & 64 & 0.053461 \\
\hline 28 & 0.021598 & 28 & 0.014071 & 65 & 0.056931 \\
\hline 29 & 0.011331 & 29 & 0.006072 & 66 & 0.020041 \\
\hline 30 & 0.022958 & 30 & 0.066294 & & \\
\hline 31 & 0.012796 & 31 & 0.011328 & & \\
\hline 32 & 0.024772 & 32 & 0.018996 & & \\
\hline 33 & 0.004504 & 33 & 0.035915 & & \\
\hline 34 & 0.006014 & 34 & 0.187508 & & \\
\hline 35 & 0.025663 & 35 & 0.878964 & & \\
\hline 36 & 0.015374 & 36 & 0.03591 & & \\
\hline 37 & 0.015747 & 37 & 0.108596 & & \\
\hline
\end{tabular}

